\title{
Pemenuhan Kebutuhan Istirahat dan Tidur pada Lansia dengan Terapi Dzikir Di PSTW Tresna Werda Budi Luhur Jambi
}

\author{
Faridah ${ }^{1}$, Iin Indrawati ${ }^{2}$ \\ ${ }^{1}$ Program Studi DIII Fisioterapi STIKes Baiturrahim Jambi \\ ${ }^{2}$ Program Studi DIII Keperawatan STIKes Baiturrahim Jambi \\ Email: taherfaridah821@gmail.com
}

Submitted : 03/12/2020

Accepted: 17/12/2020

Published: 11/01/2021

\begin{abstract}
Sleep is a form of activity that affects the quality of individual health. Insomnia is a symptom that can interfere with the activity and productivity of the elderly. Therefore the elderly must get appropriate therapy. Therapy in patients with insomnia can be in the form of pharmacological therapy or nonpharmacological therapy, but pharmacological therapy can cause an effect on the side compared to non pharmacological therapy.Tresna Werdha Budi Luhur Social Home is a nursing home in Jambi, which accommodates elderly people so that they get proper care. The number of elderly people who were there in 2010 as many as 73 homes, 37 men and 35 women. Based on a preliminary survey conducted in July 2019, the elderly generally complained of not being able to sleep soundly so that they felt weak, lethargic and not eager to do activities during the day. The sleep disturbance is felt when you wake up at night, for example listening to the full sound, the urge to urinate, and there are also those who find it difficult to fall asleep. The solution to these problems is counseling the elderly who have sleep disorders, training in the application of remembrance therapy to the elderly. The target outputs that have been implemented are the development of teaching materials in the nursing nursing course and counseling turning sheets. The method used is discussion, socialization and demonstration on counseling and practice directly with elderly dhikr therapy. The results that have been achieved are the elderly are very good and want to do this remembrance therapy if they have difficulty sleeping, but for this early stage the elderly need assistance to understand the steps of the practice of remembrance therapy.
\end{abstract}

Keywords: elderly, remembrance, rest and sleep

\begin{abstract}
Abstrak
Tidur merupakan bentuk aktivitas yang mempengaruhi kualitas kesehatan individu. Insomnia merupakan gejala yang dapat mengganggu aktivitas dan produktivitas lansia. Oleh karena itu lansia harus mendapatkan terapi yang sesuai. Terapi pada penderita insomnia dapat berupa terapi farmakolgi maupun terapi nonfarmakologi, namun terapi farmakologi dapat menimbulkan efeksamping dibandingkan terapi non farmakologi.Panti Sosial Tresna Werdha Budi Luhur merupakan panti jompo yang ada di Jambi, menampung lanjut usia agar mereka mendapatkan perawatan yang layak. Jumlah Lanjut usia yang ada dipanti tahun 2019 sebanyak 72 orang, Lakilaki 35 orang dan perempuan 37 orang. Berdasarkan survey pada bulan Juli 2019 lansia pada umumnya mengeluh tidak bisa tidur dengan nyenyak sehingga merasakan badan lemas,lesu dan tidak bersemangat melakukan aktivitas disiang harinya. Keluhan gangguan tidur ini dirasakan ketika terbangun dimalam hari misalnya mendengarkan suara berisik, keinginan berkemih, dan ada merasakan sulitnya tertidur. Solusi dari permasalahan adalah tim Kegiatan Pengabdian masyarakat memberikan penyuluhan pada lansia yang mengalami gangguan tidur, latihan penerapan terapi zikir pada lansia. Target luaran yang telah dilaksanakan adalah pengembangan bahan ajar pada mata kuliah keperawatan gerontik dan lembar balik penyuluhan. Metode yang digunakan adalah diskusi, sosilaisasi dan demonstrasi tentang penyuluhan dan praktik langsung dengan terapi dzikir. Hasil yang telah dicapai adalah lansia mau melakukan kegiatan terapi zikir bila mereka mengalami kesulitan tidur, namua untuk tahap awal ini lansia membutuhkan pendampingan untuk memahami langkah-langkah kegiatan terapi zikir.
\end{abstract}

Kata Kunci :dzikir, istirahat dan tidur, lansia 


\section{PENDAHULUAN}

Lanjut usia ( Lansia) merupakan tahap akhir dari kehidupan dan merupakan proes alamiah yang tidak dapat dihindari oleh setiap individu. Setiaplansia akan mengalami proses yang alami yaitu proses menua yang meupakan suatu proses perubahan seorang dewasa sehat menjadi seorang yang lemah dengn terjadinya perubahan fisiologi dan psikologis pada lansia sehingga terjadi gangguan pola tidur pada lansia (Bandiyah 2009).

Proses menua lansia memberikan dampak pada berbagai aspek kehidupan, baik sosial,ekonomi dan terutama kesehatan, karena dengan semakin bertambahnya usia, fungsi organ tubuh semakin menurun. Menua atau menjadi tua adalah suatu keadaan yang terjadi didalam kehidupan manusia. Proses menua merupakan proses sepanjang hidup tidak hanya dimulai pada satu waktu tertentu tetapi dimulai sejak permulaan kehidupan (Dewi, 2014). Berkaitan dengan proses menua, terdapat perubahan yangmempengaruhi penurunan aktivitas lansia. Tidur merupakan bentuk aktivitas yang mempengaruhi kualitas kesehatan individu. Ketika seseorang beranjak tua maka akan banyak memerlukan istirahat dengan membutuhkan waktu tidur yang berkualitas. Bentuk gangguan tidur yang dialami lansia adalah insomnia. Insomnia lansia disebabkan karena kurangnya kegiatan fisik sepanjang hari, tidur yang sebentar-sebentar sepanjang hari, gangguan cemas dan depresi, suasana kamar yang kurang nyaman, sering berkemih ketika malam hari dan infeksi saluran kemih (Maryam, 2008).

Kualitas tidur adalah suatu keadaan dimana tidur yang dijalani seseorang individu menghasilkan kesegaran dan kebugaran ketika terbangun. Kualitas tidur mencakup aspek kuantitatif seperti durasi tidur ,latensi tidur, serta aspek subjektif seperti tidur dalam dan istirahat (Khasanah \& Hidayati, 2012).
Gangguan tidur merupakan salah satu masalah kesehatan yang sering dialamioleh lansia karena dapat mempengaruhiaktivitas dan kinerja seharihari. Kondisi ini membutuhkan perhatian yang serius.

Pada Lansiaterjadi perubahan system neurologis yang secara fisiologis akan mengalami penurunan jumlah dan ukuran neuron pada sistem saraf pusat yang mengakibatkan lansia tidak dapat memenuhi kebutuhan tidur normalnya. Perubahan system neurologis mengakibatkan fungsi neurotransmitter pada system fisiologi neurologi menurun, sehingga distribusi norepinefrin yang meupakan zat yang merangsang tidur juga menurun. Hal tersebut menyebabkan perubahan irama sirkadian.

Perubahan irama sirkadian pada lansia ditunjukkan dengan terjadinya perubahantidur lasia apada fase NREM 3 dan 4, sehingga lansia hamper tidak memiliki fase 4 atau tidur dalam sulit memulai tidur merupakan gangguan yang paling sering dialami lansia, apabila ia berhasil masuk kekeadaan tidur, ia mengalami gangguan lain berupa tidur yang tidak berkualitas karena tidak mencapai fase tidur yang dalam (NREM) pasien sering terbangun tengah malam dan mengami mimpi buruk (Kozier, 2010)

Seorang lansia dengan kualitas tidur yang buruk akan merasa tidak nyaman dan selalu diliputi rasa gelisah, sebab tidur merupakan aktivitas konsolidasi otak untuk memulihkan kondisi tubuh . Kualitas tidur yang buruk akan menyebabkan gangguan antara lain seperti kecenderungan lebih rentan terhadap penyakit, pelupa, konfusi, disorentasi, serta menurunnya kemampuan konsentrasi dan membuat keputusan. Selain itu kemandirian lansianjuga berkurang yang ditandai dengan menurunnya partisipasi dalam aktivitas harian. Hal ini tentu berdampak buruk terhadap kualitas hidup lansia. Lansia membutuhkan kualitas 
tidur yang baik untuk meningkatkan kesehatan dan memulihkan kondisi dari sakit, adapun gangguantidur yang sering dialami lansia adalah insomnia.

Insomnia adalah gangguan tidur yang sering dikeluhkan lansia yang ditandai dengan kesulitan untuk tidur dan mempertahankan tidur. Menurut studi penelitian yang telah dilakukan University of California $40-50 \%$ orang denganlansia lebih dari 60 tahun telah mengalami gangguan tidur ( Roepke\& Ancoli, 2010) . Menurut National Sleep Fundation (2010) 67\% dari 1.508 lansia di Amerika usia 65 tahun keatas melaporkan mengalami gangguan tidur atau insomnia dan7,3\% lansia melaporkan gangguan dalam memulai tidur dan mempertahankan tidur. Prevalensi insomnia di Indonesia pada lansia tergolong tinggi yaitu sekitar 67\% dari populasiyang berusia diatas 65 tahun. Hasilpenelitian didapatkan insomnia sebagian besar dialami oleh perempuan yaitu sebesar 78,1\% dengan usia 60-74 tahun (Sulistyarini \& Santosa, 2016)

Insomnia merupakan gejala yang dapat mengganggu aktivitas dan produktivitas lansia. Oleh karena itu lansia harus mendapatkan terapi yang sesuai . Terapi pada penderita insomnia dapat berupa terapi farmakologi atau non farmakologi. Dari penelitian yang dilakukan , terapi non farmakologi menjadi pilihan karena biaya lebih murah dan lebih efektif dibandingkan dengan terapi farmakologi yang dapat menimbulkan efek samping sepertipenggunaan obat benzodiazepine yang dapat menimbulkan efek samping merasapusing, hipotensi dan distress respirasi serta memungkinkan kekambuhan setelah penghentian obat (Ghaddafi, 2010). Terapi non farmakologi memiliki kelebihan dibandingkan terapi farmakologi yang tidak menimbulkan ketergantungan dan efek samping. Salah satu terapi non farmakologi yang dapat diterapkan untuk menurunkan insomnia adalah dengan mengguakan terapi dzikir.

Terapi dzikirmerupakan penanganan non farmakologi yang dapat bermanfaat bagi lansia dengan insomnia karena tidakmemiliki efek samping. Ketika seseorang berdzikir , hal tersebut memasukkan dan menghidupkan sifatsifat dan asma asma Allah yang mempunyai kekuatan yang tak terhingga di dalam tubuh. Dengan hal tersebut merasa nyaman dantentram dan kembali seimbang. Keadaan seimbang didalam tubuh dapat mengembalikan dan menormalkan fungsi organ tubuh seperti sedia kal (Zamry, 2012) . Dengan mekanisme tersebut dimana dzikir dapat membuat jiwa merasa nyaman dan tentram sehingga dapat mencegah insomnia pada lansia.

Zikir merupakan bentuk ibadah yang sangat mudah dilakukan . Tidak seperti ibadah yang lain yang ditetapkan dan ketentuan -ketentuan lainnya. Menurut Ibnu Abbas zikir bisa dilakukan kapan sajadan dimana saja . Secara harfiah arti dzikir adalah ingat. Zikir berarti meningat Allah kita akan merasakan penjagaan dan pengawasanNya , sehingga kita menjadi tenang (Saleh, 2010)

Panti Sosial Tresna Werdha Budi Luhur merupakan panti jompo yang ada di Jambi, menampung lanjut usia agar mereka mendapatkan perawatan yang layak.Jumlah Lanjut usia yang ada dipanti tahun 2010 sebanyak 73 orang, Laki-laki 37 orang dan perempuan 35 orang. Berdasarkan survey pendahuluan yang dilakukan pada bulan Juli 2019 lansia pada umumnya mengeluh tidak bisa tidur dengan nyenyak sehingga merasakan badan lemas,lesu dan tidak bersemangat melakukan aktivitas disiang harinya. Keleuhan gangguantidurini dirasakan ketika terbangun dimalam hari misalnya mendengarkan suara berisi, keinginan 
berkemih, dan ada juga yang merasakan sulitnya tertidur.

Berdasarkan hasil survey tim pengabdian masyarakat sebagian besar responden berumur 61-70 tahun sebanyak $40.3 \%$.dengan dengan jenis kelamin perempuanyaitu 37 orang ( $57,1 \%$ ), jika dibandingkan dengan reponden laki-laki, perempuan yang tidak mengeluh insomnia hanya $40.5 \%$. Hal ini menunjukkan bahwa jenis kelamin mempengaruhi kualitas tidur seseorang. Wanita memilikikualitas tidur yang buruk disebabkan karena terjadinya penurunan fungsi hormone progesterone dan estrogen yang mempunyai reseptor dihipotalamus, sehingga memiliki andil pada irama sikardian dan pola tidur secara langsung. Kondisi psikologis meningkatkan kecemasan, gelisah dan emosi sering tidak terkontrol pada wanita akibat penurunan hormone estrogen bisa menyebabkan gangguan tidur.

Kualitas tidur dapat dipengaruhi dapat dipengaruhi oleh beberapa factor yaitu lingkungan, penyakit fisik, kelelahan, gaya hidup, stress emosional, diet, merokok dan medikasi. Lansia sering mengeluh bahwa kualitas tidurnya kurang, merasa kurang segar ketika bangun pagi hari dan letih. Hal ini diakibatkan karena sering terbangun pada malam hari untuk kekamar mandi, merasa panas, aktivitas masing-masing individu, kegiatan dalam pandi, rasa sakit seperti hipertensi, rematik. Hal ini sesuai dengan penelitian Vilasinee Ari dan Nyoman Ratep , 2017 bahwa 63,3\% lansia di Panti Jompo Tresna Warna Seraya Denpasar, Bali mayoritas geriatric yang memiliki kualitas tidur buruk adalah wanita yaitu sekitar $73.3 \%$ dibandingkan dengan pria.

Setelah dievaluasi dengan wawancara terpimpin pada lansia yang mengalami insomnia berat dan sangat berat sebanyak 16 orang melaksanaan terapi tidur secara mandiri sebanyak 11 orang , 5 orang lansia tidak melakukan terapi zikir dengan alasan lupa tahapan terapi zikir yang diajarkan, namun setelah dijelaskan tim tentang makna zikir bahwa zikir merupakan bentuk ibadah dapat dilakukan kapan dan dimana saja , dilaksanakan dengan satunya hati , fikiran dan perbuatan jika dilaksanakan dengan ikhlas maka akan timbul ketenangan dan kedamaian.

\section{TARGET DAN LUARAN}

Target yang dicapai pada Pengabdian masyarakat ini adalah:

a. Petugas Panti Sosial Tresna Werdha Jambi mampu mengidentifikasi tentang Masalah Kesehatanlansia terutama gangguan tidur pada lansia

b. Lansia mengenal dan memahami tentang tanga dan gejala gangguan tidur dan mampu mengatasinya minimal dengan terapi dzikir

Selain menghasilkan media leaflet dan poster pengabdian masyarakat ini memiliki luaran publikasi karya tulis ilmiah dan sebagai bahan ajar pada mata kuliah keperawatan gerontik.

\section{METODE PELAKSANAAN}

Kegiatan Pengabdian masyarakat dilaksanakan pada Bulan OktoberDesember2019 dengan sasaran Lansia Panti Sosial Tresna Werdha (PSTW) Budi Luhur Jambi. Tujuan dari kegiatan pengabdian ini yaitu: agar lansia lebih memahami tentang penyebab gangguan tidur yang sering terjadi dan mampu mengatasinya dengan terapi dzikirsehingga terwujud "Lansia Sehat baik jasmani maupun Rohani".

Pelaksanaan Kegiatan

Tahapan pelaksanaan kegiatan pengabdian kepada masyarakat ini adalah sebagai berikut:

1. Persiapan

a) Menyusun proposal kegiatan pengabdian kepadamasyarakat.

b) Pengadaan lembar balik untuk penyuluhan 
c) Menyiapkan presentasi gangguan tidur pada lansia dan kaitannya dengan terapi dzikir

2. PelaksanaanKegiatan

a) Perkenalan, diskusi tim dan mahasiswa serta menjelaskan kegiatan yang akan dilakukan

b) Edukasi pada lansia melalui media poster danleafleat.

c) Tanya jawab

d) Penutupan

2. Monitoring dan Evaluasi Monitoring dan evaluasi (Monev) dilakukan secara langsung kepada sasaran. Cakupan Monev dalam kegiatan ini meliputi monev perencanaan dan pelaksanaan dan evaluasi hasil.

\section{HASIL DAN PEMBAHASAN}

Pelaksanaan kegiatan masyarakat di PSTW Budi Luhur Jambi dibantu oleh Mahasiswa/mahasiswi Program Studi D3 Keperawatan STIKes Baiturrahim Jambi, dihadiri oleh 37 orang lansia.wisma 11, 12 dan 13 . Respon dari lansia sangat baik bahkanketika dilakukan demonstrasi terapi zikir ada beberapa lansia yang dapat tertidur setelah dibangunkan baru lansia terbangun lagi.

Program terapi zikir sebagai upaya menciptakan solusi bagi lansia yang mengalami masalah gangguan tidur di Panti Sosial Tresna Werdha Jambi, dapat dinilai sudah berjalan baik, namun untuk kegiatan mandiri lansia belum semua dilaksanakan dikarenakan kondisi fisik lansia .

Terapi dzikirmerupakan penanganan non farmakologi yang dapat bermanfaat bagi lansia dengan insomnia karena tidakmemiliki efek samping. Ketika seseorang berdzikir, hal tersebut memasukkan dan menghidupkan sifatsifat dan asma asma Allah yang mempunyai kekuatan yang tak terhingga di dalam tubuh. Dengan hal tersebut merasa nyaman dantentram dan kembali seimbang. Keadaan seimbang didalam tubuh dapat mengembalikan dan menormalkan fungsi organ tubuh seperti sedia kal (Zamry, 2012) . Dengan mekanisme tersebut dimana dzikir dapat membuat jiwa merasa nyaman dan tentram sehingga dapat mencegah insomnia pada lansia.

Adapun hasil yang dicapai adalah respon lansia sangat baik dan mau melakukan kegiatan terapi zikir ini bila mereka mengalami kesulitan tidur, namua katanya untuk tahap awal ini lansia membutuhkan pendampingan untuk memahami langkah-langkah kegiatan terapi zikir.

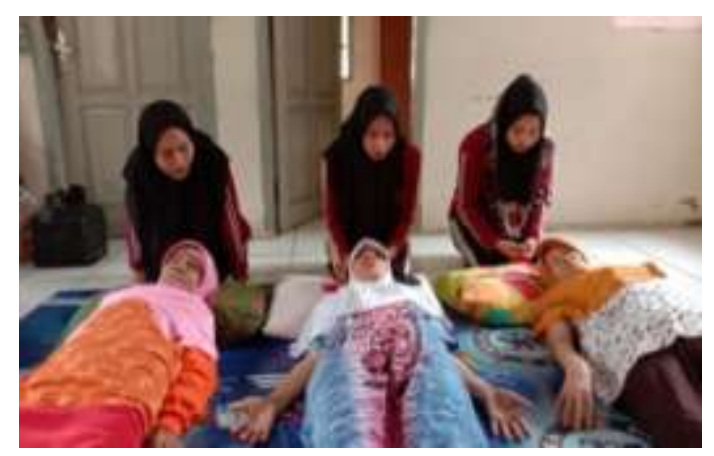

Gambar 1. Pelaksanaan terapi dzikir lansia Wanita

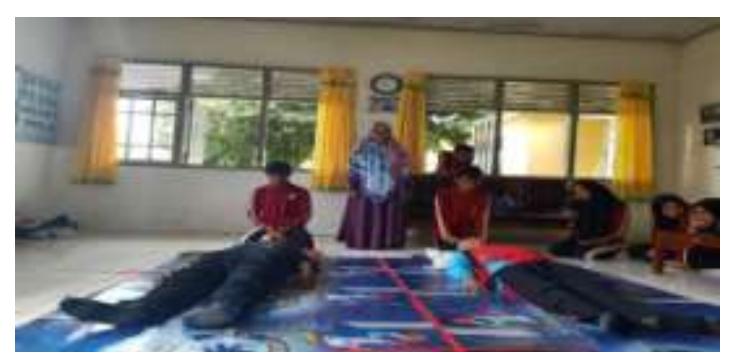

Gambar 2. Pelaksanaan terapi dzikir lansia Laki-laki

\section{KESIMPULAN DAN SARAN}

\section{Kesimpulan}

Setelah tim melaksanakan kegiatan pengabdian masyarakat lansia yang hadir mulai mengerti dan memahami tentang hangguan tidur dan cara mengatasi dengan terapi dzikir 


\section{Saran}

Hendaknya terapi zikir ini terus dapat dilakukan secara berkesinambungan di PSTW Budi Luhur Jambi , baik dalam terapi kelompok ataupun antar wisma karena ziki juga merupakan bentuk ibaah yang sangat mudah dilakukan, disamping itu menyarakan kepada lansia untuk tidak mengkonsumsi kopi, rokok dan mengurangi minum ketika mau tidur sehingga dapat mengganggu tidur.

\section{UCAPAN TERIMAKASIH}

Pengabdian masyarakat ini dapat terwujud dan selesai dengan baik karena adanya bantuan dari berbagai macam pihak maka dari itu penulis mengucapkan terima kasih kepada Ketua STIKES Baiturrahim Jambi, Kaprodi D-III keperawatan STIKES Baiturrahim Jambi, Ibu Pimpinan PSTW Budi Luhur Jambi memfasilitasi kegiatan pengabdian masyarakat ini.

\section{DAFTAR PUSTAKA}

Bandiyah, (2009).Lanjut Usia dan Keperawatan Gerontik. Yogyakarta :Nuha Medika

Dewi (2014) . Angka Kejadian dan Faktor-faktor yang mempengaruhi Gangguan Tidur (Insomnia) Pada Lansia di Panti Sosial Tresna Werda Wana Seraya Denpasar Bali. Jurnal Universitas Udayana

Kumar V.K.H. Ratep.N Intisari Sains Medis 2017, Volume 8 Number 2: 151-154. P-ISSN:2503-3638, EISSN:2089-9084

Khasanah , K \& Hidayati (2012) Kualitas Tidur Lansia Balai Rehabilitasi Sosial Mandiri Semarang. Jurnal Nursing Studies

Maryam, R.R (2008) . Mengenal Usia Lanjut dan Perawatannya. Jakarta : Salemba Medika

Kozier (2010) . Buku Ajar Fundamental Keperawatan Edisi 7 Vol. 2 Jakarta : EGC
Saleh (2010). Berzikir untuk Kesehatan Saraf Jakarta 